\title{
Effect of Friction Testing of Metals on Particle Emission
}

\author{
J. Kouam, V. Songmene, A. Djebara, and R. Khettabi
}

(Submitted May 14, 2010; in revised form April 28, 2011)

\begin{abstract}
Metallic particles emitted during manufacturing processes can represent a serious danger for occupational safety. The mechanisms responsible for these particle emissions include two- and three-body frictions; Moreover, such particles can also be emitted during several other processes, including mechanical braking. To be in a position to devise ways to reduce these particle emissions at the source, it is important to know their size, quantity, and distribution, as well as the relationships between operating conditions and particle emissions. This article investigates nanoparticle and microparticle emissions during two friction tests: one (setup 1: pin in rotation only) simulates the friction occurring during mechanical braking actions, and another (setup 2: pin in rotation and translation) simulates the friction taking place at the tool-workpiece interface during metal cutting processes. The materials tested were aluminum alloys (6061-T6 and 7075T6), and the pin used was a carbide cylinder. Particle emission was monitored using the Scanning Mobility Particle Sizer (SMPS) for nanoparticles, and the Aerosol Particle Sizer (APS) for microparticles. It was found that friction produces more nanoparticles than microparticles, and that total particle emission can be reduced by operating at low or at high sliding speeds.
\end{abstract}

Keywords aluminum alloys, carbide, friction, microparticles, nanoparticles

\section{Introduction}

Researchers (Ref 1-5) have studied particle emissions, and their results and proposed models become limited and unpractical when the particle size is small. Ko et al. (Ref 6) modeled the phenomenon of frictional particle production by proposing a special microscopic roughness design in which surface asperity shapes were considered as randomly spaced cylindrical corrugations. Their study shows the effect of part surface roughness on particle emission. Akarca et al. (Ref 7) found that during the sliding wear of the A356 aluminum alloy, wear particles are generated by the nucleation of voids and the propagation of microcracks at a certain depth beneath the surface. Fang (Ref 8) and Fang and Ho (Ref 9) proposed a special surface texture design to control surface asperities to identify the mechanism of particle detachment by friction, as well as a predictive mathematical model. However, the Fang (Ref 8) and Fang and Ho (Ref 9) model uses dimensions for the surface texture that are not realistic since the shape and the distribution of surface asperities of most mechanical parts are random.

A very limited number of researchers, including Zemzemi et al. (Ref 10), have studied the effect of the friction occurring during machining on particle emission; Zemzemi et al. (Ref 10) designed and used a special tribometer to study the friction

J. Kouam, V. Songmene, A. Djebara, and R. Khettabi, Department of Mechanical Engineering, École de technologie supérieure (ÉTS), 1100 Notre-Dame Street West, Montréal, QC H3C 1K3, Canada. Contact e-mails: Jules.Kouam@etsmtl.ca and victor.songmene@etsmtl.ca.

taking place during orthogonal turning operations. Zemzemi et al. (Ref 11) were the first authors in the machining field to isolate the friction effect during machining and to propose a numerical model simulating this friction. They identified a friction model capable of describing the friction effect on toolchip-workpiece interfaces. They used the new tribometer designed by Zemzemi et al. (Ref 10) to simulate higher contact pressures under high sliding velocities to study the forces, friction coefficients, and heat partition coefficient. Their model is suitable for turning processes, but not easy enough to be applied for other processes, such as milling and drilling.

Balout et al. (Ref 12) and Songmene et al. (Ref 13) identified the friction at the tool-workpiece interface as a contributor to the total metallic particle emission occurring during machining (Fig. 1), but the authors did not study the friction alone. Songmene et al. (Ref 13) identified five particle emission sources during drilling: shearing action, deformation and friction of chips, deformation and friction on the tool-chip interface, friction on tool-workpiece, and friction of chips in drill flutes. They also recognized the difficulty of isolating each source for a separate study. The experimental setup proposed in this article addresses one of these difficulties by simulating particle emissions at the tool-workpiece interface using a friction test in which the tool is animated with two motions (rotational speed and a translation, setup 2, Fig. 2). This study will help in evaluating the amount of metallic particles emitted in Mode 4.

The main objective of this research is to study the effect of friction between the tool and workpiece on metallic particle emission. Two setups were designed and tested on pairs of materials consisting of aluminum alloy workpieces and a carbide tool used as a pin. The first one (setup 1: pin in rotation only) simulates the friction occurring during mechanical braking actions, and the second (setup 2: pin in rotation and translation) simulates the friction taking place at the toolworkpiece interface during metal cutting processes. The main 


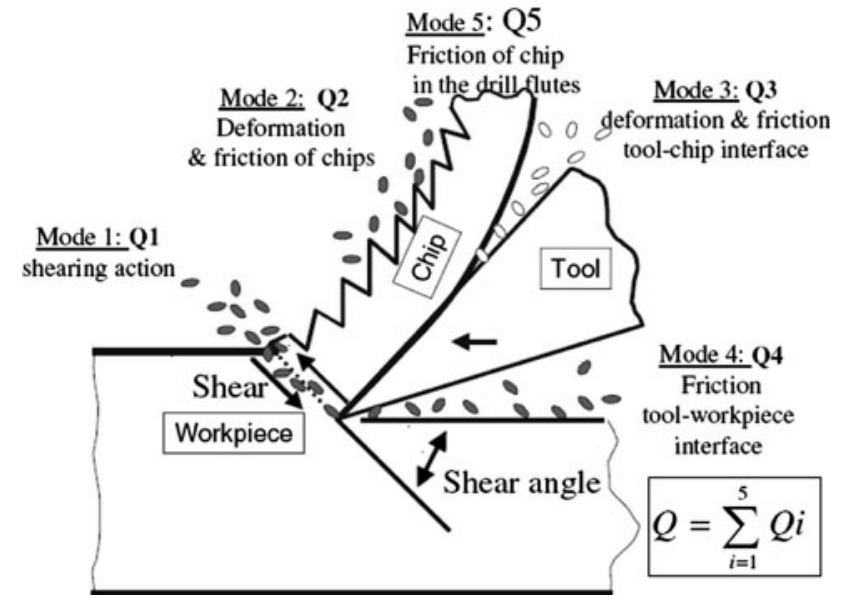

Fig. 1 Schematic representation of possible sources of metallic particle emission during machining (Ref 12, 13)

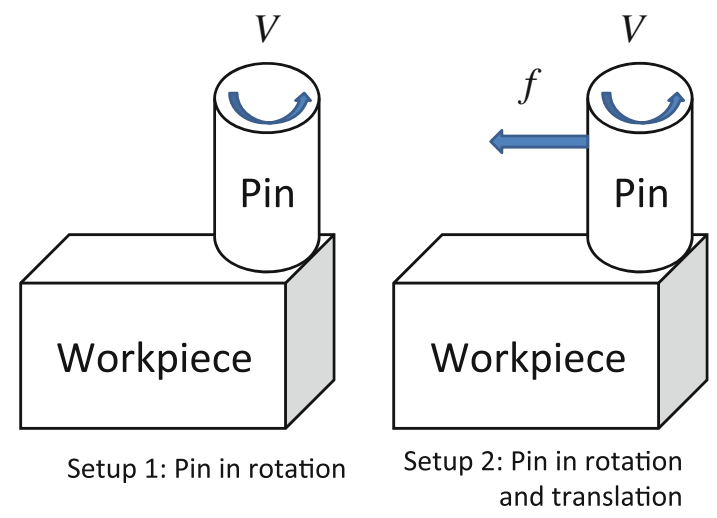

Fig. 2 Different setups used during friction tests

difference between this study and that of Zemzemi lies in the fact that this study involves two movements (rotation and translation of the pin), which affords better simulation of the milling process. The authors have also applied higher sliding speeds (up to $1000 \mathrm{~m} / \mathrm{min}$ ), comparable to the speeds currently used in the machining industry.

\section{Experimental Procedure}

Tests were carried out on two aluminum materials (6061-T6 and 7075-T6), and cutting forces were obtained using a table dynamometer connected to a computer. Particle emission was measured with an APS (Aerosol Particle Sizer, particle size ranging from 0.5 to $20 \mu \mathrm{m}$ ) and an SMPS (Scanning Mobility Particle Sizer, equipped with a nano DMA (Differential Mobility Analyzer), particle size ranging from 7 to $300 \mathrm{~nm}$ ). Their experimental application has been described by Khettabi et al. (Ref 14). These two units, which measure mass concentration, particle number concentration and specific area concentration as a function of aerodynamic diameter, are connected to a computer.

The machining unit used was a Computer Numerical Control (CNC) milling machine (28000 rpm), to which a $30 \times 30 \times 20$ cubic centimeter Plexiglas box was added on the table, allowing the process to be carried out in a closed environment. This increased the measurement efficiency, as fewer particles were capable of escaping into the environment. Polluted air within the closed box was driven into the particle measurement unit through a polyester tube $10 \mathrm{~mm}$ in diameter. The tube is short (about $304.8 \mathrm{~mm}$ ), and kept upright to minimize particle loss within.

The following conditions and parameters were used during friction tests:

- Pin rotational speed $(V): 100-1000 \mathrm{~m} / \mathrm{min}$

- Pin displacement speed $(f)$ for setup 2: $250 \mathrm{~m} / \mathrm{min}$

- Pin: uncoated carbide, $19.05 \mathrm{~mm}$ diameter

Figure 2 presents the two different experimental setups used. For setup 1, the pin is in rotation without displacement, and is engaged in the workpiece material with a circular surface contact. In setup 2, the pin rotates at different set spindle speeds, and translates along the workpiece material at a $50 \mathrm{~m} / \mathrm{min}$ linear speed.

\section{Results and Discussion}

\subsection{Nanoparticle Emission}

Figure 3(a) and (b) show typical particle emission results as a function of the particle diameters obtained using SMPS. It is seen that without displacement (Fig. 2, setup 1; Fig. 3a), the particle number is higher than in the case where the pin rotates and translates (Fig. 3b). The particle concentration becomes smaller for larger aerodynamic particles.

In addition to the data presented in Fig. 3, the system also computes the total particle number, mass, and specific surfaces presented in Fig. 4-6, as a function of sliding speeds.

For the 7075-T6 aluminum alloy, the speed at which maximum particle emission occurs (about $500 \mathrm{~m} / \mathrm{min}$ ), is independent of the setup used (Fig. 4b, 5b, 6b). Conversely, for the case of the 6061-T6 aluminum alloy, the maximum particle emission during friction occurs at $200 \mathrm{~m} / \mathrm{min}$ in setup 1 and at $400 \mathrm{~m} / \mathrm{min}$ in setup 2. This observation indicates a possible interaction between the materials and the setup at the critical speed. On the other hand, their mechanical properties as well as their hardness (53 HRA for 7075-T6 and 38 HRA for 6061-T6) could have played an important role.

Figure 7(a) and (b) compare the total particle number concentrations obtained during friction and milling (grooving) tests on 6061-T6 and 7075-T6. The milling tests were done at $0.165 \mathrm{~mm} / \mathrm{rev}$ feed rate using a carbide endmill, $19.05 \mathrm{~mm}$ in diameter. The depth of cut was $1 \mathrm{~mm}$ and the radial immersion, $100 \%$ of the tool diameter. Three different cutting speeds were tested in milling: 300, 750, and $1200 \mathrm{~m} / \mathrm{min}$. For 6061-T6, the particle emissions were higher in milling tests compared to friction tests (setups 1 and 2). The same observation was made for the 7075-T6 material, but particle emission was 10 times higher for the 6061-T6 material in milling than in friction tests, while it was only two times for 7075-T6. It thus appears that the contribution of friction to particle emission during a machining process such as milling can vary with the workpiece material used. This observation can be explained by the fact that each of the two materials has a different toughness, and the hardness of the 7075-T6 is higher than that of the 6061-T6. This result is being further investigated with other materials and conditions, and taking into account the particle size distribution. 
6061-T6 material : friction at $500 \mathrm{~m} / \mathrm{min}$ cutting speed in setup 1

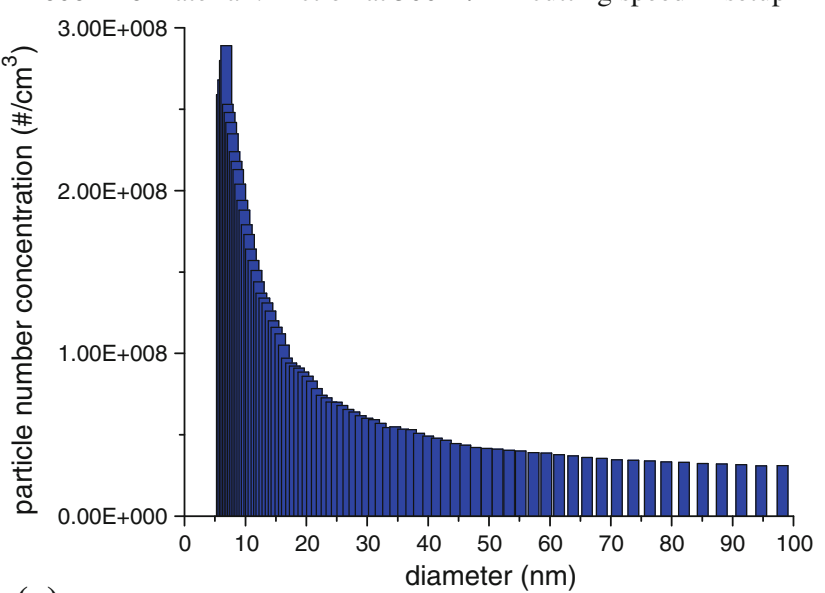

(a)
6061-T6 material : friction at $500 \mathrm{~m} / \mathrm{min}$ cutting speed in setup 2

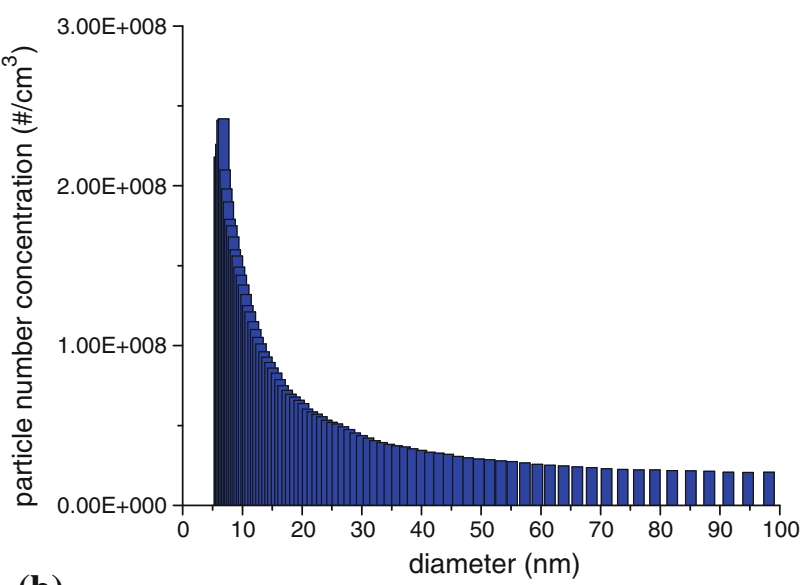

(b)

Fig. 3 Particle number at different diameters for 6061-T6 at $500 \mathrm{~m} / \mathrm{min}$ cutting speed from SMPS: (a) in setup 1 and (b) in setup 2

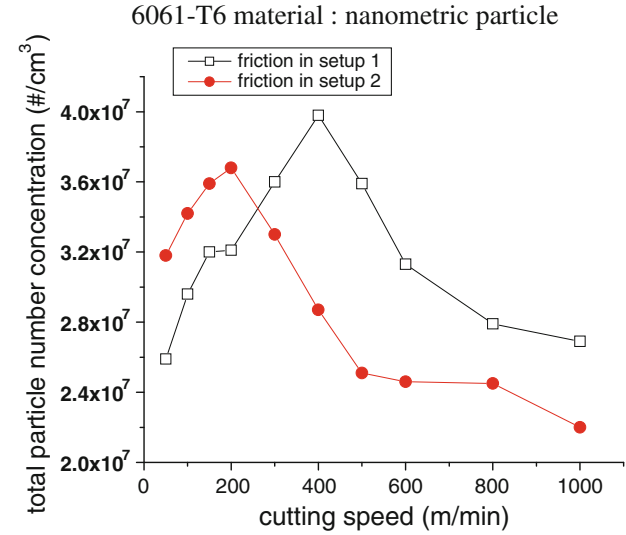

(a)

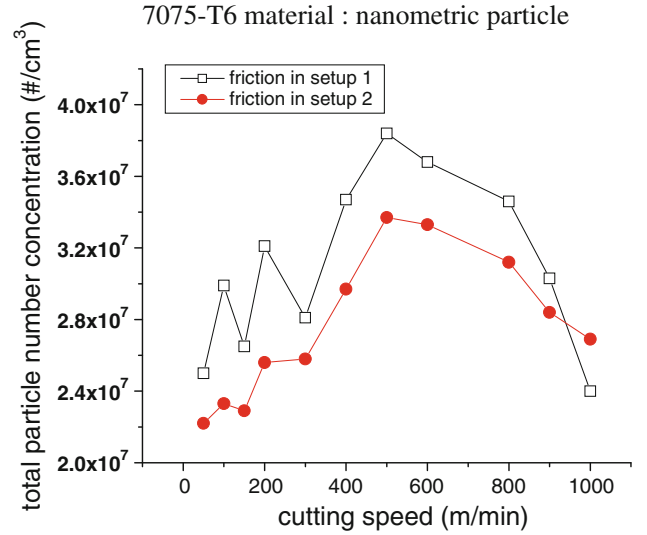

(b)

Fig. 4 Total particle number concentration at different speeds obtained from SMPS. (a) 6061-T6 and (b) 7075-T6

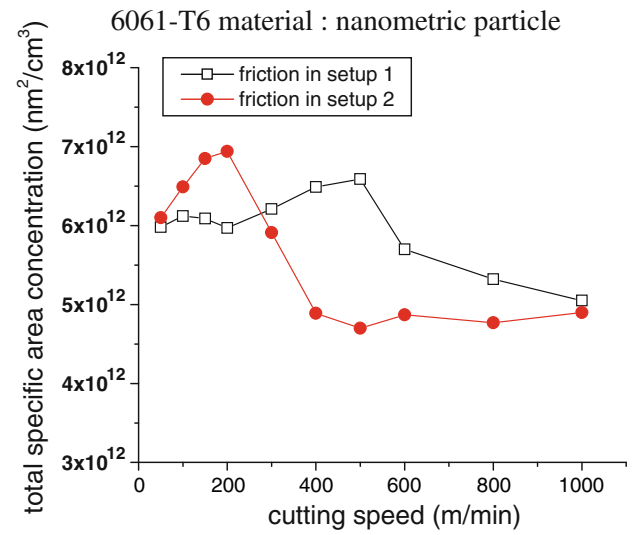

(a)

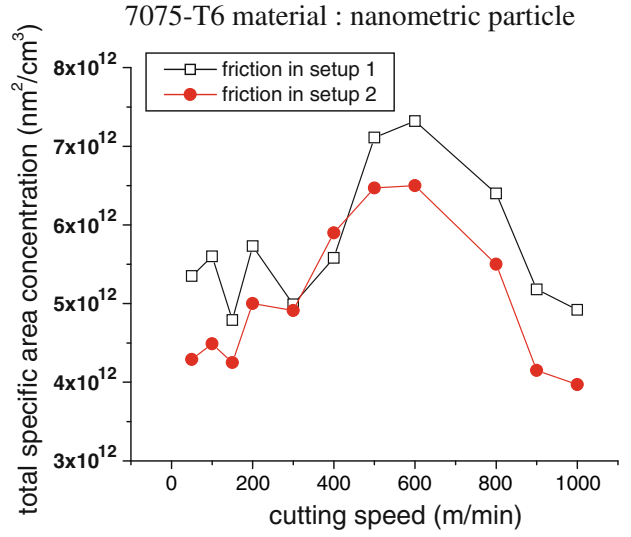

(b)

Fig. 5 Total specific area concentration at different speeds obtained from SMPS. (a) 6061-T6 and (b) 7075-T6

\subsection{Microparticle Emission}

Figure 8(a) and (b) show typical particle emission results, as a function of the aerodynamic diameter obtained from APS, for particle diameters ranging from 0.5 to $30 \mu \mathrm{m}$. It is observed that for microparticles, the particle number is approximately the same in setup 1 as in setup 2 .

Figures 9-11 present the total concentration for the particle number, the specific area and the specific mass of microparticles 


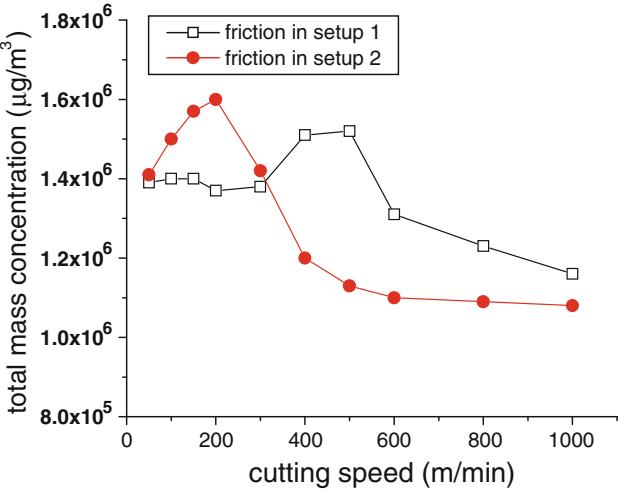

(a)

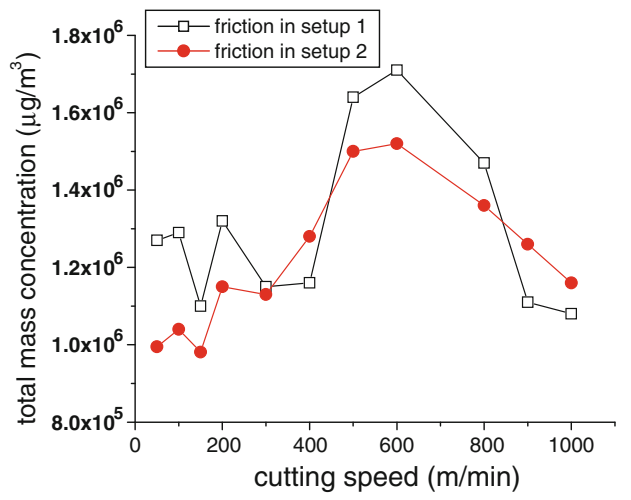

(b)

Fig. 6 Total mass concentration at different speeds obtained from SMPS. (a) 6061-T6 and (b) 7075-T6

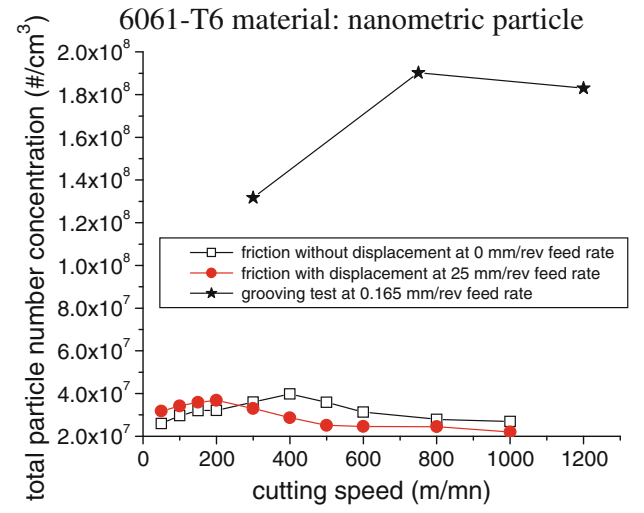

(a)

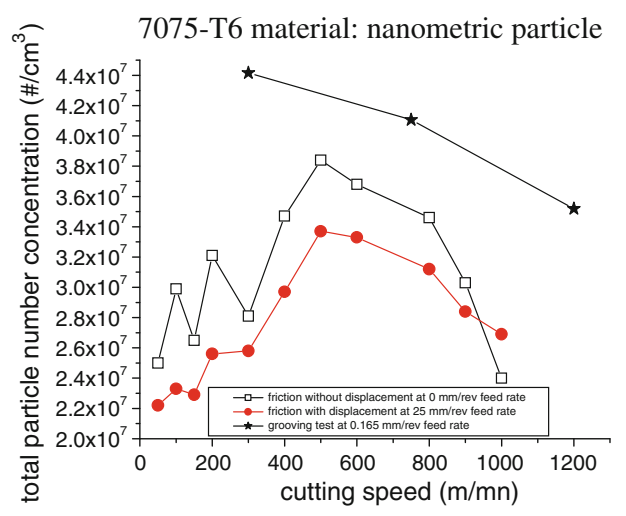

(b)

Fig. 7 Comparison of total particle number concentration in friction and grooving tests. (a) 6061-T6 and (b) 7075-T6
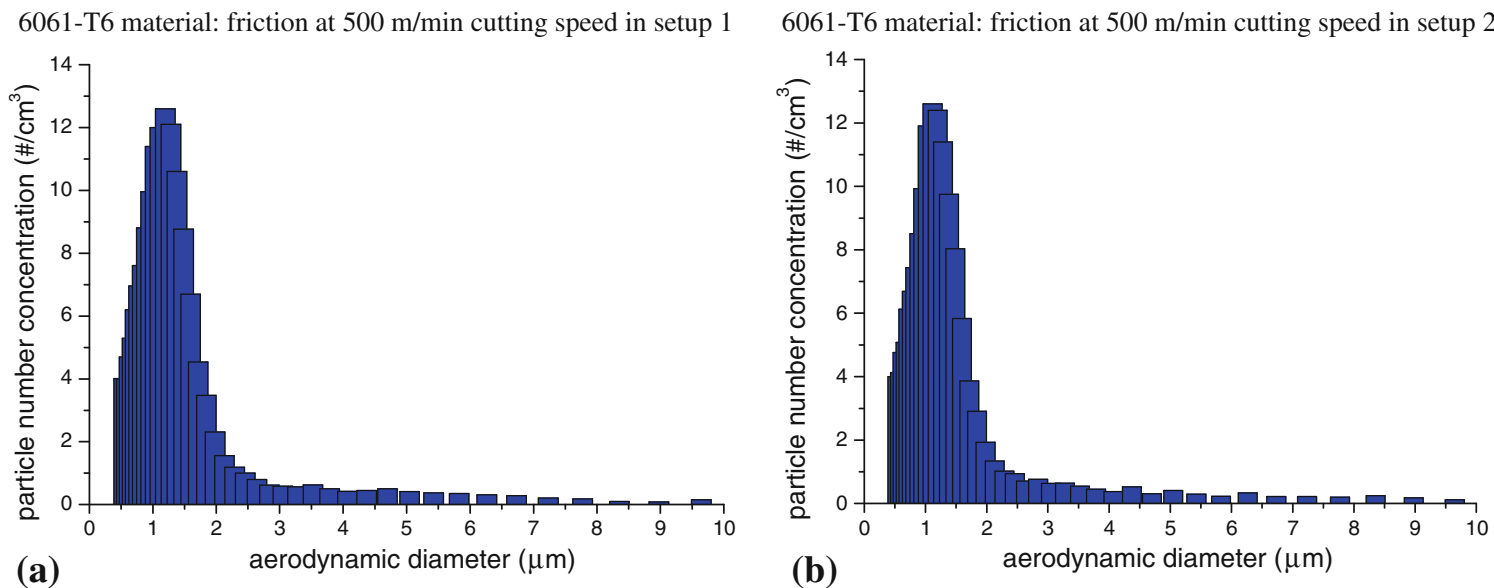

Fig. 8 Particle numbers at different aerodynamic diameters for $6061-\mathrm{T} 6$ at $500 \mathrm{~m} / \mathrm{min}$ cutting speed: (a) in setup 1 and (b) in setup 2

as a function of applied speeds. In general, the microparticle emission obtained in setup 1 (pin in rotation only) is comparable to that obtained in setup 2 (pin in rotation and translation). At very low speeds, the amount of particles is low; it then increases, reaches the maximum value, and eventually decreases. These two speed regimes have been observed by Khettabi et al. (Ref 15) in their study on turning, and by Kouam et al. (Ref 16) in their study on drilling. 


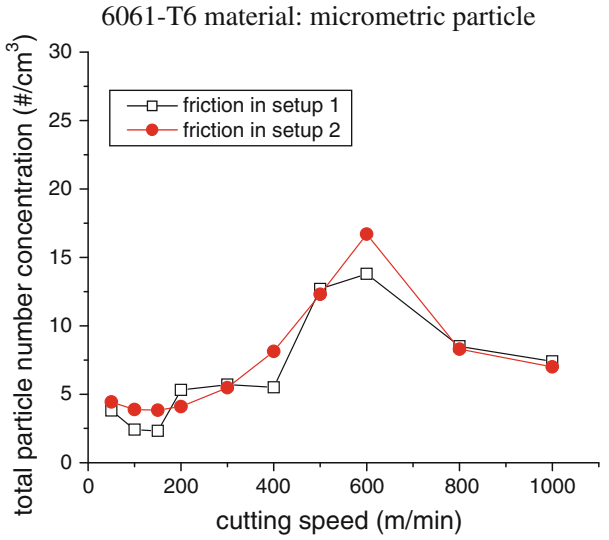

(a)

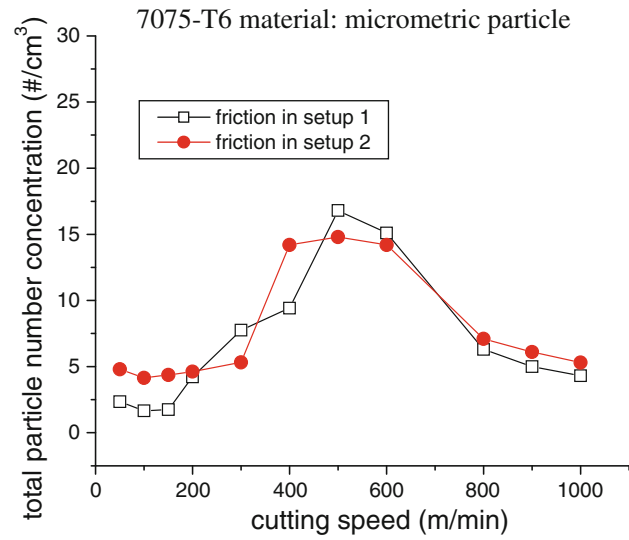

(b)

Fig. 9 Total particle number concentrations at different speeds obtained from APS. (a) 6061-T6 and (b) 7075-T6

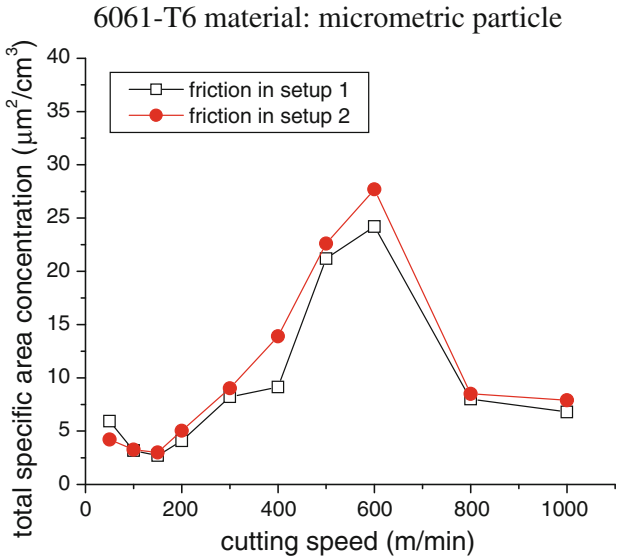

(a)
7075-T6 material: micrometric particle

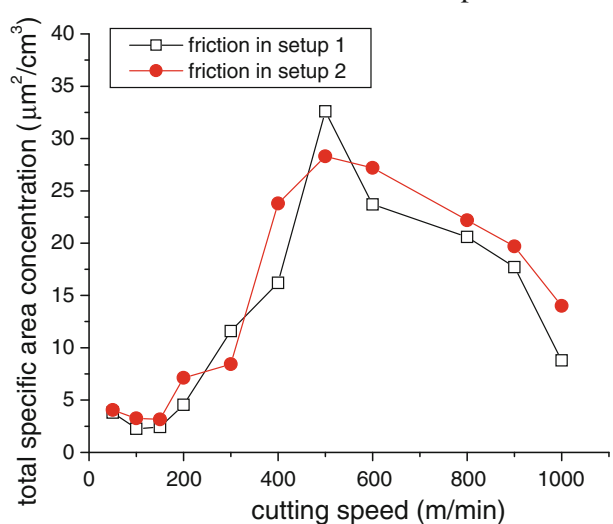

(b)

Fig. 10 Total specific area concentrations at different cutting speeds obtained from SMPS. (a) 6061-T6 and (b) 7075-T6

6061-T6 material: micrometric particle

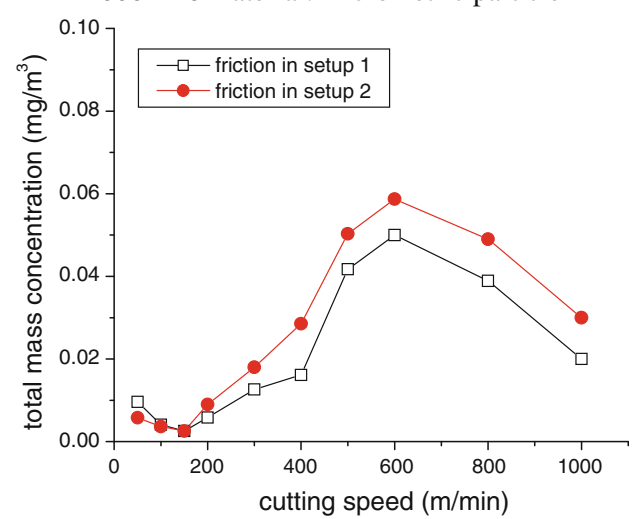

(a)
7075-T6 material: micrometric particle

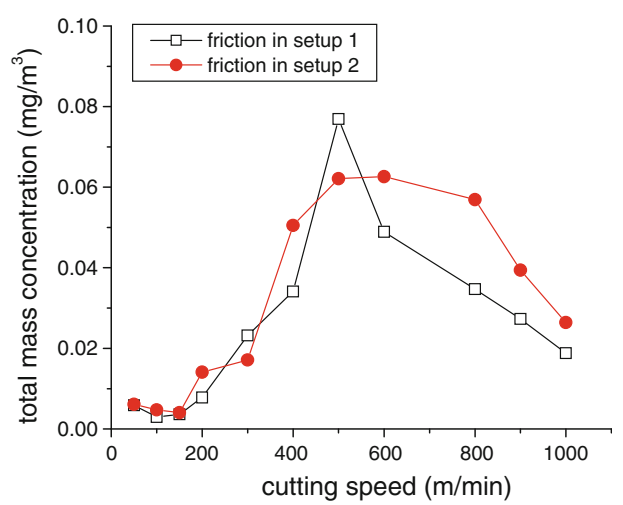

(b)

Fig. 11 Total particle number concentrations at different cutting speeds obtained from APS. (a) 6061-T6 and (b) 7075-T6 
The critical speed required for microparticle emission to be at a maximum is the same for the two setups ( 1 and 2 ) of both aluminum alloys studied. The maximum particle emission value for material types 7075-T6 and 6061-T6 occurs at speeds of 600 and $500 \mathrm{~m} / \mathrm{min}$, respectively.

The results on particle emission (Fig. 6-7, 9-11) indicate that by operating at high speed (about $1000 \mathrm{~m} / \mathrm{min}$ ) for the aluminum alloys tested, the emission of both nanoparticles and microparticles due to friction is low. This is also the case for very low speeds (below $200 \mathrm{~m} / \mathrm{min}$ ), but the use of the low speed regime is not recommended, as it would lower the productivity when machining.

\subsection{Cutting Forces}

Figure 12(a) and (b) present the forces $\left(F_{x y}\right)$ recorded during the friction tests. $F_{x y}$ is obtained from the equation as follows:

$F_{x y}=\sqrt{F_{x}^{2}+F_{y}^{2}}$

For both materials, the forces are slightly higher in setup 2 (pin in rotation and translation) than in setup 1 (pin in rotation only). This observation can be explained by the fact that as the pin translates, it encounters asperities and peaks of newer surfaces.
In general, the forces obtained in friction tests are very low (less than $10 \mathrm{~N}$ ) as compared to milling forces (about $140 \mathrm{~N}$ ), Fig. 12. Therefore, the energy required for friction at the tool workpiece interface is very limited compared to that used for shearing and cutting. The load on the pin (applied force) was kept low to simulate only the friction; otherwise, some material work hardening might have taken place.

Figure 13 presents the roughness at different cutting speeds for the 6061-T6 and 7075-T6 materials. The roughness values were obtained using the Mitutoyo S-J400 equipment. These figures show that the roughness decreases when the cutting speed increases in setup 1 and in setup 2. This observation confirms the fact that the surface finish improves as the cutting speed increases, and is itself confirmed by the study of Fu et al. (Ref 17), in which they show that the surface roughness decreases when the cutting speed of aluminum is increased. Their study involved the high speed (about $1500 \mathrm{~m} / \mathrm{min}$ ) milling of aluminum, and they used the following equation for the roughness, $R_{\mathrm{a}}$ :

$R_{\mathrm{a}}=C V^{-b_{1}} f^{b_{2}} a_{\mathrm{p}}^{b_{3}} a_{\mathrm{e}}^{b_{4}}$

where $V$ is the cutting speed, $f$ the feed rate, $a_{\mathrm{p}}$ the cutting depth, and $a_{\mathrm{e}}$ the cutting width.

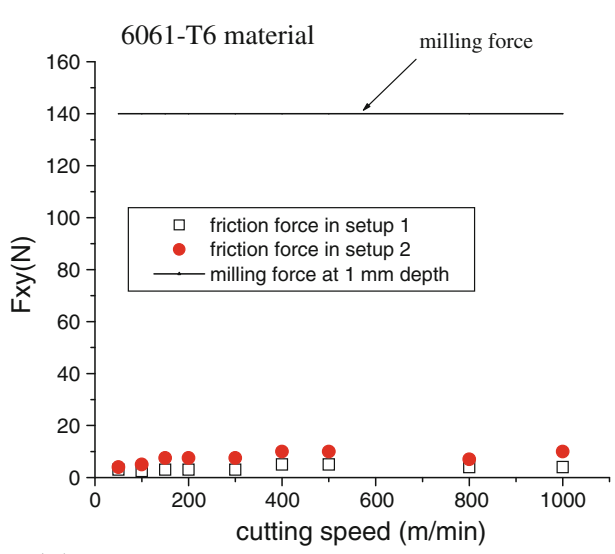

(a)

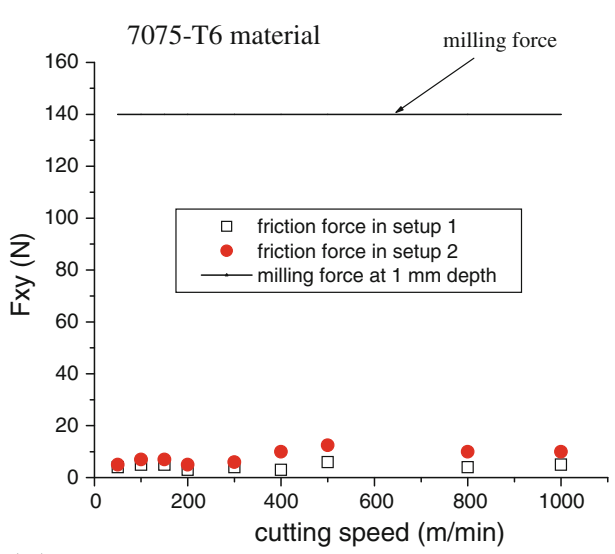

(b)

Fig. 12 Cutting forces $\left(F_{x y}\right)$ as a function of cutting speeds in setup 1 and setup 2. (a) 6061-T6 and (b) 7075-T6

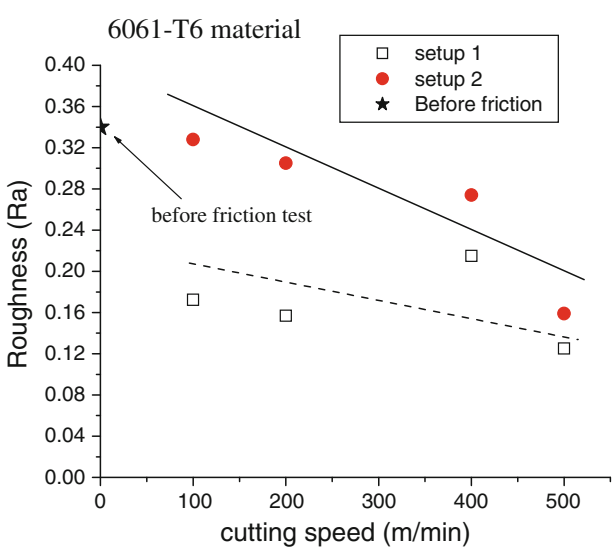

(a)

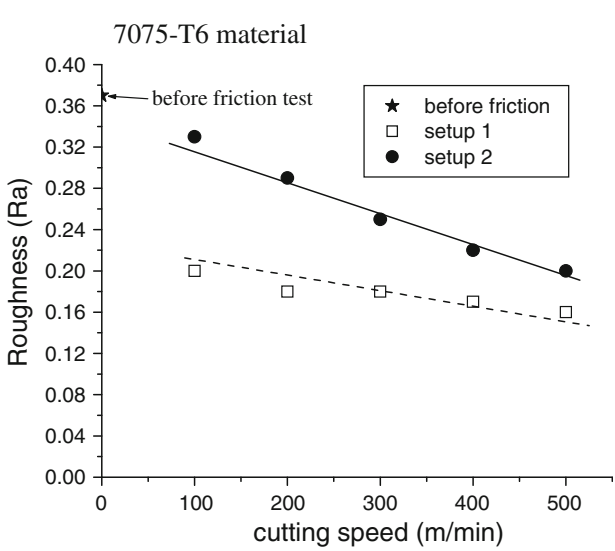

(b)

Fig. 13 Roughnesses at different cutting speeds in setup 1 and setup 2. (a) 6061-T6 and (b) 7075-T6 


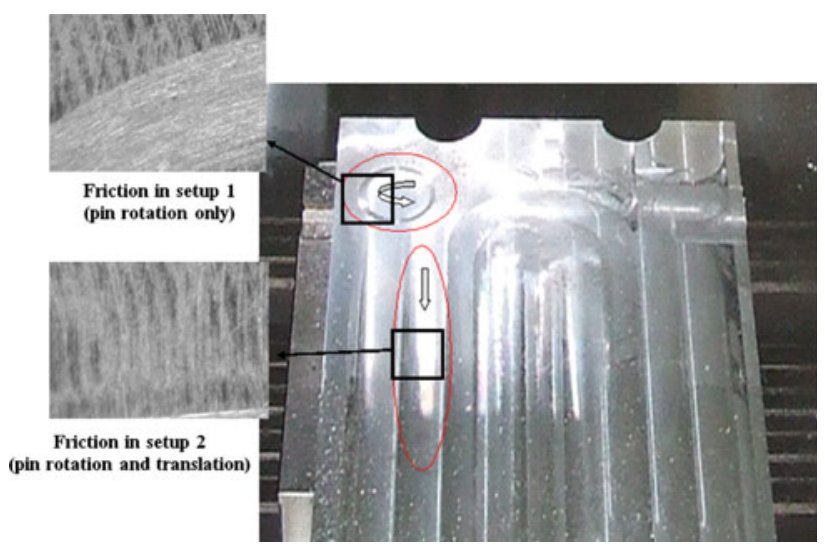

Fig. 14 Optical microscopic images of workpiece after friction tests (100 m/min 6061-T6 material)

$C, b_{1}, b_{2}, b_{3}$, and $b_{4}$ (all positive) are materials and cutting condition constants. The cutting speed $(V)$ is the only parameter with a negative exponent, and the roughness $R_{\mathrm{a}}$ decreases when the cutting speed increases.

Shaw (Ref 18) proposed a representative friction model for machining, expressed in terms of the relationship between the real contact area $\left(A_{\mathrm{r}}\right)$ and the apparent contact area $(A)$ :

$\frac{A_{\mathrm{r}}}{A}=1-e^{-B N}$

where $B$ is a material constant, and $N$ is the applied load.

The Shaw model (Eq 3) was improved by Khettabi (Ref 19) to take into account the effect of the interface temperature $(\Delta T)$ :

$\frac{A_{\mathrm{r}}}{A}=1-e^{-\left(B_{1} N+B_{2} \Delta T\right)}$

where $B_{1}$ and $B_{2}$ are constants.

The temperature involved in friction is proportional to the sliding velocity, and so, by increasing the cutting speed, the real surface interface will be affected as a result of the material softening leading to asperities flattening. This improves the surface finish.

Figure 14 shows the optical microscopic images obtained in setups 1 and 2. The images were obtained using a type Stereozoom 7 Bausch and Lomb microscope and a Firewire type Clemex camera with $1280 \times 1024$ pixels. The magnification used was 2.5 times. Figure 14 shows that at the same cutting speed, the surface finish is better in setup 1 than in setup 2, the same as was observed in Fig. 13.

\section{Conclusions}

In this study, the effect of speed and pin motion on metallic particle emission during friction was studied.

- Two distinct regimes of cutting speeds characteristic of the particle emission during friction were observed:

(1) A low-speed regime, where particle emission is low, and increases with speed;
(2) A high-speed regime, where particle emission decreases as the speed increases. These two speed regimes are delimited by a critical speed at which the maximum particle emission rate is seen. For microparticles, the cutting speed at which the maximum emission occurs does not change with the setups, the conditions and the materials tested. A similar observation was found in the case of nanoparticles for the 7075-T6 material, but not for the 6061-T6 material.

- Overall, friction produced more ultrafine particles than fine particles at all rotational speeds and for all materials tested.

- As expected, the particle emission in friction was low compared to that obtained in the machining process (milling). The particle number in friction was 2-10 times lower than in machining, depending on the workpiece material and conditions used.

- For the materials and conditions tested, the total particle emission can be reduced by operating at very low or at very high sliding speeds.

Future study will involve brittle materials and a comparison with particle emissions occurring during machining to assess the contribution of friction to particle emission during metal cutting processes.

\section{Acknowledgments}

This research study is part of a project on nanoparticle emission funded by the NanoQuébec and the Institut de Recherche RobertSauvé en Santé et Sécurité du Travail (IRSST). The authors also acknowledge discussions with Y. Cloutier, M. Viens, S. Hallé, and F. Morency.

\section{References}

1. D. Chen, M. Sarumi, and S.T.S. Al-Hassani, Computational Mean Particle Erosion Model, Wear, 1998, 214, p 64-73

2. Z. Zhang, L. Zhang, and Y.-W. Mai, Modelling Friction and Wear of Scratching Ceramic Particle-Reinforced Metal Composites, Wear, 1994, 176, p 231-237

3. M.J. Hadianfard, J.C. Healy, and Y.-W. Mai, Fracture Toughness of Discontinuously Reinforced Aluminum 6061 Matrix Composites, J. Mater. Sci., 1993, 28, p 6217-6221

4. E. Rabinowicz, Penetration Hardness and Toughness Indicators of Wear Resistance, Mechanical Engineering Publ. Ltd, Bury St. Edmunds, 1987, p 197-203

5. E. Rabinowicz, Shape of Adhesive Wear Particles, ASME, New York, NY, 1985, p 1377-1386

6. P.L. Ko, S.S. Iyer, H. Vaughan, and M. Gadala, Finite Element Modelling of Crack Growth and Wear Particle Formation in Sliding Contact, Wear, 2001, 251, p 1265-1278

7. S.S. Akarca, W.J. Altenhof, and A.T. Alpas, Characterization and Modeling of Subsurface Damage in a 356 Aluminum Alloy Subjected to Multiple Asperity Sliding Contacts, Minerals, Metals and Materials Society, Warrendale, PA, 2005, p 107-120

8. H.-W. Fang, Characteristic Modeling of the Wear Particle Formation Process from a Tribological Testing of Polyethylene with Controlled Surface Asperities, J. Appl. Polym. Sci., 2007, 103, p 587-594

9. H.-W. Fang and Y.-C. Ho, Preparation of UHMWPE Particles and Establishment of Inverted Macrophage Cell Model to Investigate Wear Particles Induced Bioactivities, J. Biochem. Biophys. Methods, 2006, 68, p 175-187

10. F. Zemzemi, W. Ben Salem, J. Rech, A. Dgui, and P. Kapsa, Development of a Friction Model for Numerical Simulation of Dry 
Machining of AISI 4142 Steel with TiN Coated Carbide Cutting Tools, Proc. of First International Conference on Sustainable Manufacturing SM1, Montréal, Canada, October 17-18, 2007, p 81-89

11. F. Zemzemi, J. Rech, W. Ben Salem, A. Dgui, and P. Kapsa, Identification of a Friction Model at Tool/Workpiece Interfaces in Dry Machining of AISI, 4142 Treated Steels, J. Mater. Process. Technol., 2009, 209(8), p 3978-3990

12. B. Balout, V. Songmene, and J. Masounave, An Experimental Study of Dust Generation During Dry Drilling of Pre-Cooled and Pre-Heated Workpiece Material, J. Manuf. Process., 2007, 9(1), p 23-34

13. V. Songmene, B. Balout, and J. Masounave, Clean Machining: Experimental Investigation on Dust Formation: Part I, Int J. Environ. Conscious Mach. (ECDM), 2008, 14(1), p 1-16

14. R. Khettabi, V. Songmene, and J. Masounave, Effects of Speeds, Materials and Tool Rake Angle on Dust Emission During Dry Cutting, J. Mater. Eng. Perform., 2008, doi:10.1007/s11665-009-9551-2
15. R. Khettabi, V. Songmené, and J. Masounave, Influence of Machining Processes on Particles Emission, Proc. of 49th Annual Conference of Metallurgists of CIM, Vancouver 2010, p 277-288

16. J. Kouam, J. Masounave, and V. Songmene, Pre-Holes Effect on Cutting Forces and Particle Emission During Dry Drilling Machining, Proc. of 49th Annual Conference of Metallurgists of CIM, Vancouver 2010, p 253-263

17. X. Fu, Y. Pan, Y. Wan, and X. Ai, Research on Predictive Model Surface Roughness in High Speed Milling for Aluminum Alloy 7050T7451, Proc. 2010 International Conference on Computing, Control and Industrial Engineering, 2010, p 186-189

18. M.C. Shaw, Metal Cutting Principles, 2nd ed., Oxford University Press, New York, 2005

19. R. Khettabi, "Modélisation des émissions de particules microniques et nanométriques en usinage," Ph.D. thesis, Ecole de technologie supérieure, ÉTS, 2009, 198 p (in French) 